\title{
Linear pneumatic actuator
}

\author{
Mihai Avram ${ }^{1, *}$, Constantin Niţu ${ }^{1}$, Constantin Bucşan ${ }^{1}$, and Bogdan Grămescu ${ }^{1}$ \\ ${ }^{1}$ Politehnica University of Bucharest, Dpt. of Mechatronics and PrecisionMechanics, Bucharest, \\ Romania
}

\begin{abstract}
The paper presents a linear pneumatic actuator with short working stroke. It consists of a pneumatic motor (a simple stroke cylinder or a membrane chamber), two $2 / 2$ pneumatic distributors "all or nothing" electrically commanded for controlling the intake/outtake flow to/from the active chamber of the motor, a position transducer and a microcontroller. There is also presented the theoretical analysis (mathematical modelling and numerical simulation) accomplished.
\end{abstract}

\section{Introduction}

The actual stage and the future development of pneumatics make it a high technology domain. The successes guaranteed by the results of some fundamental and especially applicative "fascinating" researches [1], in the direction of diminishing the negative effects produced by the physical properties of the working fluid: low viscosity and high compressibility. These are the main difficulties in building high performance pneumatic systems.

The informatisation of the pneumatics systems is an important qualitative step ahead for the domain [2]. The concept of pneutronics was developed by the synergetic joining of three domains: pneumatics-electronics-informatics. So, pneutronic actuating systems were born.

The configuration of such a system may vary from simple actuating circuits to complex structures, controlled with programmable automatons or computers. The basic elements of such a system are the proportional pneumatic servo-systems [3 - 5]. In the structure of the system are also included sensors and transducers, electronic circuits for signal processing, $\mathrm{A} / \mathrm{D}$ and $\mathrm{D} / \mathrm{A}$ converters, controllers or microprocessors.

Unfortunately these systems are very expensive and they are rarely used. This is the reason why sustained efforts are made in order to reduce the costs $[6,7]$.

In this paper a pneumatic linear actuator is proposed. It is in fact a pneutronic positioning system that does not use proportional devices.

\section{The structure of the intelligent pneumatic actuator}

Figure 1 shows the original principle scheme of the actuator to be developed. It consists of the following elements:

${ }^{*}$ Corresponding author: mavram02@yahoo.com 
$B P A$ - the pneumatic supply block;

$M P L$ - the short stroke pneumatic motor;

$B E C$ - the electronic command block;

$\mathrm{Tr}-$ the position transducer.

The pneumatic supply block $B P A$ delivers into the active chamber of the motor a pressure proportional with an electric command signal: $P_{c}=f\left(x_{c}\right)$.

For the short stroke pneumatic motor one can choose between special short stroke motor, a chamber with a membrane or a corrugated tube.

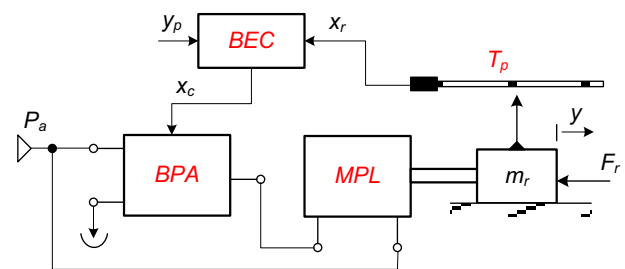

Fig. 1. The original principle scheme of the actuator.

The functional scheme of the actuator is shown in figure 2.

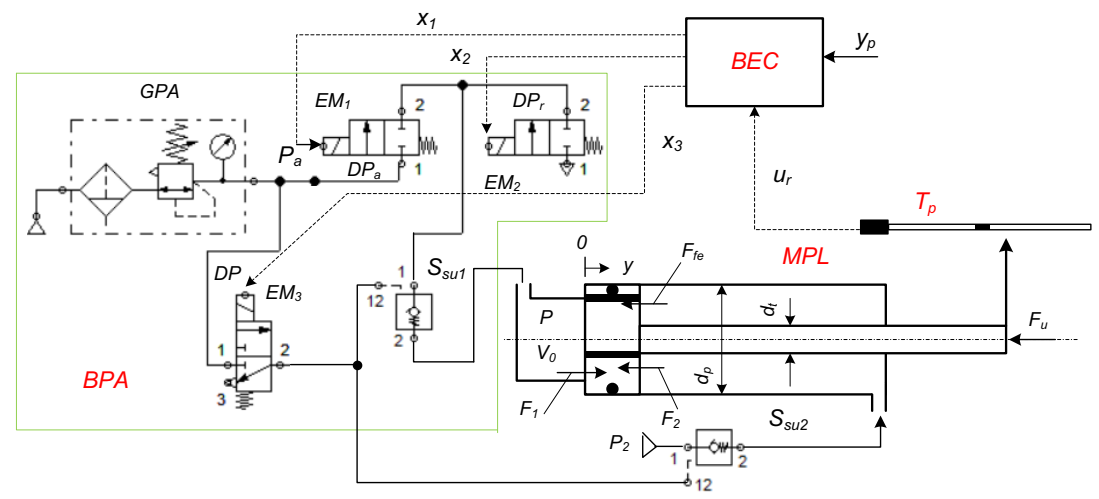

Fig. 2. The functional scheme of the actuator.

The pneumatic supply block consists of the following devices:

- the $2 / 2$ pneumatic control valves $D P_{a}$ and $D P_{e}$, with preferential position, electrically controlled;

- two one-way valves, relievable, $S_{s u 1}$ and $S_{s u 2}$, pneumatically controlled;

- the $3 / 3$ pneumatic control valve DC, with preferential position, electrically controlled;

- the air supply group.

The control valves $D P_{a}$ and $D P_{e}$ connect the active chamber of the rod less pneumatic linear motor MPL to the pneumatic supply or to the atmosphere; the chamber has the volume $\mathrm{V}$.

The rod chamber of the motor is permanently connected to the pressure supply. When the control valve $D P_{a}$ is commanded the pressure $\mathrm{P}$ increases; when the pressure force $F_{l}$ becomes greater than the force $F_{2}+F_{f e}$ (the pressure force and the elastic friction force respectively), the mobile assembly of the motorstartsmoving. The position transducer Tp gives information on the position of the mobile assembly to the electronic command block BEC; at this level, the actual position is in real time compared with the programmed position; according to the result of this comparison, digital command signals are or are not generated for the control valves $D P_{a}$ and $D P_{e}$. 
The logic of these signals is the following:

- $\quad$ if $y<y_{p}-\varepsilon$ then $x_{3}=1, x_{1}=1$ and $x_{2}=0$;

- $\quad$ if $y_{p}-\varepsilon \leq y \leq y_{p}+\varepsilon$ then $x_{3}=0, x_{1}=0$ and $x_{2}=0$;

- $\quad$ if $y>y_{p}+\varepsilon$ then $x_{3}=1, x_{1}=0$ and $x_{2}=1$,

where: " 1 " corresponds to the case when the electromagnet of the control valve $\left(D P, D P_{a}\right.$ or $D P_{e}$ ) is commanded, and " 0 "when the electromagnetic not commanded.

\section{The theoretical analysis of the intelligent pneumatic actuator}

The static and dynamic performances of a system can be determined theoretically or experimentally. In this stage, without a physical model of the actuator, only a theoretical analysis can be performed.

Taking into consideration the functional scheme and imposing the maximum stroke, the useful force and the supply pressure, the devices composing the system can be predimensioned and then they can be chosen from the producers catalogues.

The next step is the elaboration of the mathematical model and then the simulation of the system functioning. So, the first information on the dynamic behavior of the system is obtained.

Mathematical modeling and numerical simulation are laborious; require knowledge from many domains besides pneumatics (numerical analysis, automated systems theory, computer programming, informatics, optimizing methods etc.).

A pneumatic system is characterized by a large number of variables and interactions that are difficult to quantify, so a rational and systematic approach strategy for modeling and simulation is required.

The mathematical model of a pneumatic system is highly non-linear [8], [9], [10], and the numerical simulation is used to determine the capability of the system to perform a given task, in terms of dynamic behavior.

The equations of the mathematical model are the following:

a. The mobile assembly moving equation is given by:

$$
m_{r} \cdot \frac{d^{2} y}{d t^{2}}=F_{1}-F_{2}-F_{f e}-F_{0}-F_{u}
$$

where:

$$
\begin{gathered}
F_{1}=P \cdot S_{1} \\
F_{2}=P_{2} \cdot S_{2} \\
F_{0}=P_{0} \cdot S_{t} \\
F_{f e}=\mu \cdot \pi \cdot d_{p} \cdot b_{p} \cdot\left(P_{2}-P\right)=k_{1} \cdot\left(P_{2}-P\right) \\
S_{1}=\frac{\pi}{4} \cdot d_{p}^{2} \\
S_{2}=\frac{\pi}{4} \cdot\left(d_{p}^{2}-d_{t}^{2}\right)
\end{gathered}
$$




$$
S_{t}=\frac{\pi}{4} \cdot d_{t}^{2}
$$

In these conditions, equation (1) can be written:

$$
\frac{d v}{d t}=\frac{1}{m_{r}} \cdot\left\{\left(S_{1}+k_{1}\right) \cdot P-\left[\left(S_{2}+k_{1}\right) \cdot P_{2}+S_{t} \cdot P_{0} \cdot+F_{u}\right]\right\}
$$

where:

$$
\frac{d y}{d t}=v
$$

b. The pressure $P$ differential equation is given by:

$$
\frac{\mathrm{dP}}{\mathrm{dt}}=\frac{\chi \cdot \mathrm{R} \cdot \mathrm{T}_{\mathrm{a}}}{\mathrm{V}_{0}+\mathrm{S}_{1} \cdot \mathrm{y}} \cdot \dot{\mathrm{m}}-\frac{\chi \cdot \mathrm{P} \cdot \mathrm{S}_{1}}{\mathrm{~V}_{0}+\mathrm{S}_{1} \cdot \mathrm{y}} \cdot \mathrm{V}
$$

where:

$$
\begin{gathered}
\dot{\mathrm{m}}=\frac{\mathrm{K} \cdot \mathrm{P}_{\mathrm{a}} \cdot \mathrm{S}_{\mathrm{n}}}{\sqrt{\mathrm{T}_{\mathrm{a}}} \cdot \mathrm{N}\left(\frac{\mathrm{P}}{\mathrm{P}_{\mathrm{a}}}\right)} \\
\mathrm{N}\left(\frac{\mathrm{P}}{\mathrm{P}_{\mathrm{a}}}\right)= \begin{cases}1 & \text { if } 0 \leq \mathrm{P} / \mathrm{P}_{\mathrm{a}} \leq 0,528 \\
\mathrm{a} \cdot\left[\left(\frac{\mathrm{P}}{\mathrm{P}_{\mathrm{a}}}\right)^{\frac{2}{\chi}}-\left(\frac{\mathrm{P}}{\mathrm{P}_{\mathrm{a}}}\right)^{\frac{(\chi+1)}{\chi}}\right]^{\frac{1}{2}} & \text { if } \frac{\mathrm{P}}{\mathrm{Pa}_{\mathrm{a}}}>0,528\end{cases}
\end{gathered}
$$

where the coefficients are given by [1]:

$$
\begin{gathered}
\chi=1,4[-] \\
\mathrm{R}=287.04\left[\frac{\mathrm{m}^{2}}{\mathrm{~s}^{2} \cdot \mathrm{K}}\right] \\
\mathrm{K}=0.04042\left[\frac{\sqrt{\mathrm{K}} \cdot \mathrm{s}}{\mathrm{m}}\right] \\
\mathrm{a}=2.6143[-]
\end{gathered}
$$

When functioning, the following cases can be found:

1. If $R=\left(S_{1}+k_{1}\right) \cdot P-\left[\left(S_{2}+k_{1}\right) \cdot P_{2}+S_{t} \cdot P_{0}+F_{u}\right]<0$ than the displacementy $=$ 0 and a filling process of a fix volume $V_{0}$ takes place, which produces the increase of the pressure in this volume to the value:

$$
P_{l i m}=\frac{\left(S_{2}+k_{1}\right) \cdot P_{2}+S_{t} \cdot P_{0}+F_{u}}{S_{1}+k_{1}}
$$

In these conditions the speed $v=0$, and the pressure differential equation (4) becomes:

$$
\frac{d P}{d t}=\frac{\chi \cdot R \cdot T_{a}}{V_{0}} \cdot \dot{m}
$$

The initial pressure in the volume $V_{0}$ is the atmospheric pressure.

1.1. First, the flowing regime through the nominal area $S_{n}$ of the control valve $D P_{a}$ is a sonic one, according to the pressure ratio value: $P \leq 0.528 \cdot P_{a}$. In this case, the mass flow rate is given by: 


$$
\dot{m}=\frac{K \cdot P_{a} \cdot S_{n}}{\sqrt{T_{a}}}
$$

and the pressure differential equation becomes:

$$
\frac{d P}{d t}=\frac{\chi \cdot R \cdot T_{a}}{V_{0}} \cdot \frac{K \cdot P_{a} \cdot S_{n}}{\sqrt{T_{a}}}=c_{1} \cdot P_{a}
$$

where:

$$
c_{1}=\frac{\chi \cdot R \cdot \sqrt{T_{a}} \cdot K \cdot S_{n}}{V_{0}}\left[S^{-1}\right] .
$$

Integrating equation (9) the pressure is obtained:

$$
P=c_{1} \cdot P_{a} \cdot t+c_{2}
$$

The integration constant $c_{2}$ is found from the condition that at $t=0$ the pressure in the volume $V_{0}$ is $P=P_{0}$ and its value is $c_{2}=P_{0}$.

So, the pressure is given by:

$$
P=c_{1} \cdot P_{a} \cdot t+P_{0}
$$

The pressure in the volume $V_{0}$ will reach the critical value $P_{c r t}=0.528$. $P_{a}$ (corresponding to the end of the sonic flowing regime) at the time:

$$
t_{c r t}=\frac{0.528 \cdot P_{a}-P_{0}}{c_{1} \cdot P_{a}}[s]
$$

1.2. From this point the flowing regime becomes subsonic. The equation (8) becomes:

$$
\frac{d P}{d t}=\frac{\chi \cdot R \cdot T_{a}}{V_{0}} \cdot \frac{K \cdot P_{a} \cdot S_{n}}{\sqrt{T_{a}}} \cdot a \cdot\left[\left(\frac{P}{P_{a}}\right)^{2 / \chi}-\left(\frac{P}{P_{a}}\right)^{(\chi+1) / \chi}\right]^{1 / 2}
$$

This equation can be written as:

$$
\frac{d r}{d t}=c_{3} \cdot\left[r^{2 / \chi}-r^{(\chi+1) / \chi}\right]^{1 / 2}
$$

where:

$$
\begin{gathered}
c_{3}=\frac{\chi \cdot R \cdot \sqrt{T_{a}} \cdot K \cdot S_{n}}{V_{0}} \cdot a=c_{1} \cdot a \\
r=\frac{P}{P_{a}}
\end{gathered}
$$

Equation (12) can be written:

$$
\frac{d r}{r^{1 / \chi} \cdot \sqrt{1-r^{(\chi-1) / \chi}}}=c_{3} \cdot d t
$$

Using the substitution $1-r^{\frac{(\chi-1)}{\chi}}=z^{2}$ the equation can be integrated and the solution is given by: 


$$
z=-\frac{\chi-1}{2 \cdot \chi} \cdot c_{3} \cdot t+c_{4}
$$

from which the value of the pressure is obtained:

$$
P=\left[1-\left(c_{4}-\frac{\chi-1}{2 \cdot \chi} \cdot c_{3} \cdot t\right)^{2}\right]^{\frac{\chi}{\chi-1}} \cdot P_{a}
$$

The constant $c_{4}$ is obtained from the condition that at $t=t_{c r t}$ the pressure in the volume $V_{0}$ is $P=P_{c r t}$ and its value is given by:

$$
c_{4}=\sqrt{1-0.528^{\frac{\chi-1}{\chi}}}+\frac{\chi-1}{2 \cdot \chi} \cdot a \cdot\left(0.528-\frac{P_{0}}{P_{a}}\right)
$$

The pressure $\mathrm{P}$ has the value $P_{\text {lim }}$ at $t=t_{\text {lim }}$. Imposing the condition for these values to check the equation (15), the equation of $t_{\text {lim }}$ is obtained:

$$
t_{\text {lim }}=\frac{2 \cdot \chi}{(\chi-1) \cdot c_{3}} \cdot\left[c_{4}-\sqrt{1-\left(\frac{P_{\text {lim }}}{P_{a}}\right)^{\frac{\chi-1}{\chi}}}\right][s]
$$

2. If $R>0$ then the mobile assembly moves and a filling process of a variable volume $V$ takes place. In this case the dynamic behavior of the system is described by the mathematical model consisting of equations (2), (3), (4), (5) and (6).

The numerical simulation of the system functioning was performed using Matlab Simulink.

3. The following constructive and functional parameters values where imposed:

$d_{p}=40[\mathrm{~mm}], \quad d_{t}=28[\mathrm{~mm}], \quad b_{p}=4[\mathrm{~mm}], \quad l_{0}=20[\mathrm{~mm}], \quad \mu=0,3[-], \quad F_{u}=$ $100[N]$

$d_{n}=3 m[m], P_{a}=P_{2}=4[b a r], T_{a}=293,15[K]$.

The programmed position value was imposed $y_{p}=200 \mathrm{~mm}$.

Figure 3 shows the simulation model. Running the model, the following characteristics were obtained:

- $\quad P=P(t)-$ figures $4 \mathrm{a}$ and $4 \mathrm{~b}$;

- $\quad y=y(t)-$ figures $4 \mathrm{c}$ and $4 \mathrm{~d}$;

- $\quad \dot{y}=\dot{y}(t)$ - figures $4 \mathrm{e}$ and $4 \mathrm{f}$.

The effective start moment ist $=\mathrm{t}_{\text {lim }}=0.0102 \mathrm{~s}$, as shown in the diagrams from figures 4.a, 4.c and 4.e. In this moment the pressure in the chamber becomes $P=P_{\text {lim }}=$ 3.5 bar.

When the distance to the programmed position reaches a pre-settled value, the command of the control valve $D P_{a}$ is cancelled, the air supply of the volume $V$ stops, and the mobile assembly continue to move due to the inertia.

The speed of the mobile assembly decreases to the value $v=v_{f}=0.1 \mathrm{~m} / \mathrm{s}$. When the conditiony $\geq \mathrm{y}_{\mathrm{p}}-$ cis fulfilled, the movement stops, due to a braking system (not discussed until now). 


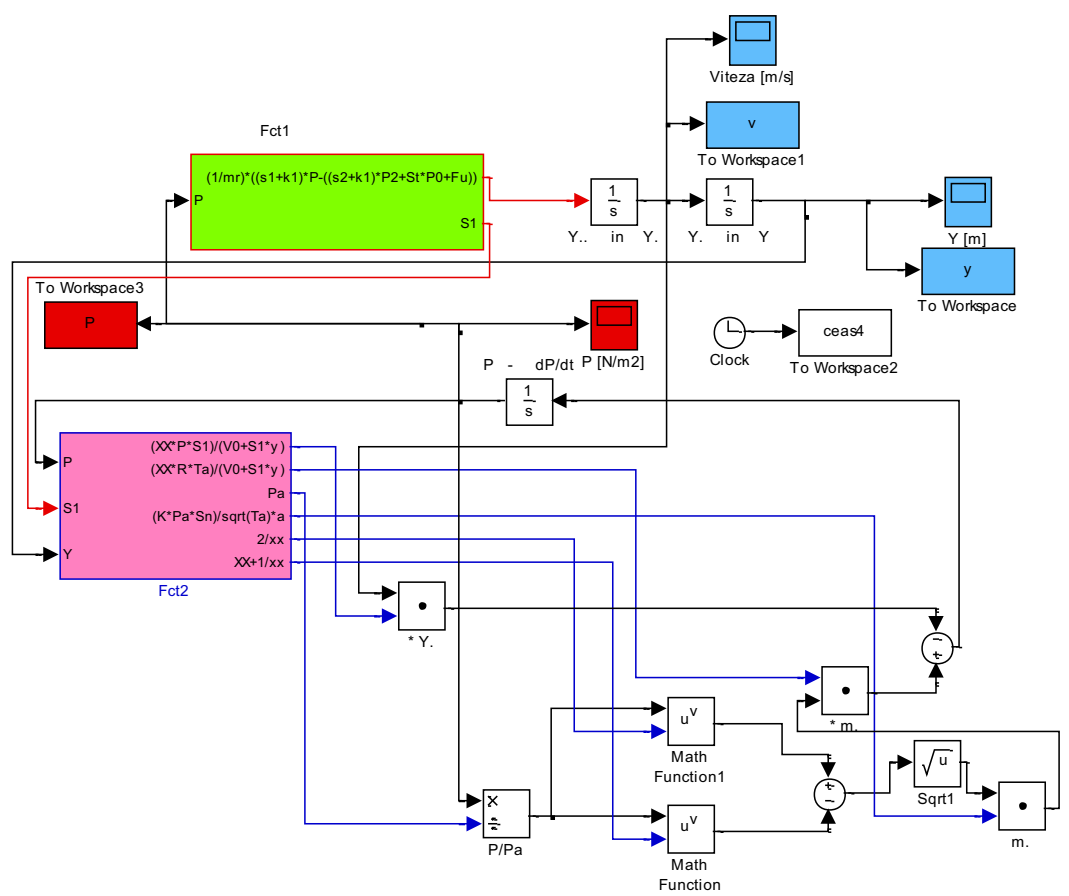

Fig. 3. The simulation model.
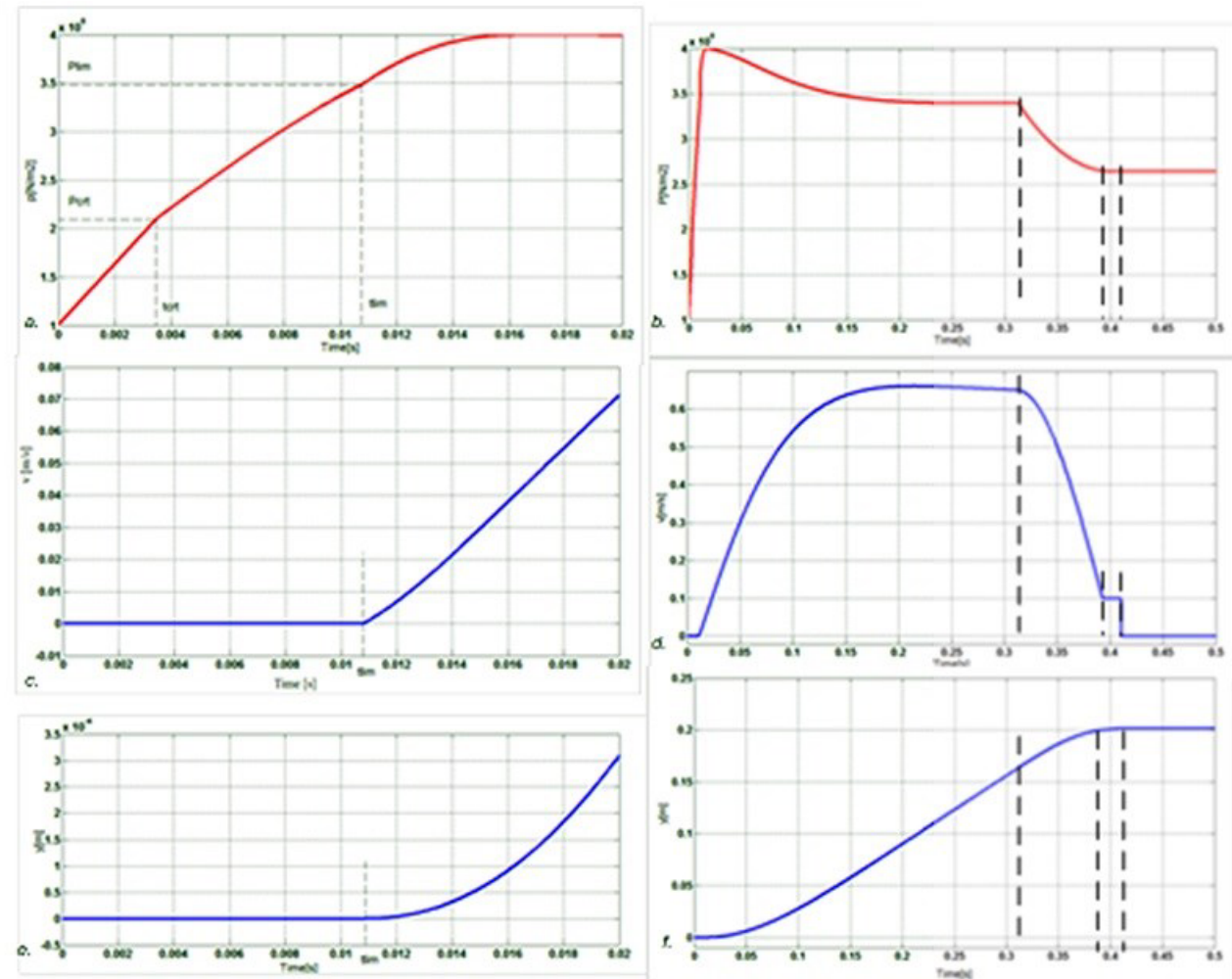

Fig. 4. The characteristics obtained by running the model. 


\section{Conclusions}

The proposed pneumatic linear actuator allows the positioning of a pay load in any point of the working stroke with an imposed accuracy. The structure of the actuator is original, very simple, using common devices, most of them being standardized. Using two $2 / 2$ control valves, "all or nothing" electrically controlled, an accurate control of the pressure in the working active volume can be obtained and the desired position can be reached.

The theoretical analysis of the system, performed on the basis of the developed mathematical model, confirmed the anticipated behavior of the actuator, according to the results obtained by integrating the model using the graphical programming environment Matlab Simulink.

The future approach will be the construction of the experimental model of the actuator. The command system will use a microcontroller and the working programs will integrate different variants of command and control algorithms. The results will be presented in a future paper.

\section{References}

1. G. Vogel, E. Mühlberger, L'univers fascinant de la pneumatique (Würzburg Vogel, 2001)

2. M. Avram, C. Bucsan, Sisteme de actionare pneumatic inteligente (Ed. Politehnica PRESS, Bucuresti, 2014)

3. M. Avram, D. Duminica, C. Udrea, V. Gheorghe, Hidronică şi pneutronică - Aplicaţii (Ed. Universitară, București, 2008)

4. M. Avram, Acţionări hidraulice şi pneumatice - Echipamente şi sisteme clasice şi mecatronice, (Ed.Universitară, Bucureşti, 2005)

5. G. Belforte, A.M. Bertetto, L. Mazza, Pneumatico - curso completo (Ed. Technichenuove, Milano, 1998)

6. K. Ahn, S. Yokota, Mechatronics, 15(6), 683 (2005)

7. R. B. Van Varseveld, G.M. Bone, IEEE/ASME Transactions of Mechatronics 2(3), 195 (1997)

8. C. Valdiero, C.S. Ritter, C.F. Rios, M. Rafikov, Proceedings of the 9th Brazilian Conference on Dynamics Control and their Applications, Serra Negra, Brasil, 198 (2010)

9. Z. Varga, P. Keski-Honkola, 25, 01096 (available at http://www.epj-conferences.org or http://dx.doi.org/10.1051/epjconf/20122501096, 2012)

10. T. Kimura, S.Hara, T. Fujita, T. Kagawa, Control Engineering Practice 5(10), 1385 (1997) 